\title{
Safety and efficacy of biodegradable polymer-coated thin strut sirolimus-eluting stent vs. durable polymer-coated everolimus-eluting stent in patients with acute myocardial infarction
}

\author{
Paweł Gąsior ${ }^{1}$, Marek Gierlotka ${ }^{2,3}$, Krzysztof Szczurek-Katanski ${ }^{4}$, Marcin Osuch ${ }^{4}$, Magda Roleder ${ }^{1}$, \\ Michal Hawranek ${ }^{5}$, Mariusz Gasior ${ }^{5}$, Wojciech Wojakowski ${ }^{1}$, Lech Polonski \\ ${ }^{1}$ Department of Cardiology and Structural Heart Diseases, Medical University of Silesia, Katowice, Poland \\ $23^{\text {rd }}$ Department of Cardiology, Silesian Centre for Heart Diseases, Zabrze, Poland \\ ${ }^{3}$ Department of Cardiology, University Hospital, Faculty of Natural Sciences and Technology, University of Opole, Opole, Poland \\ ${ }^{4}$ Scanmed, Krakow, Poland \\ ${ }^{5} 3^{\text {rd }}$ Department of Cardiology, School of Medicine with the Division of Dentistry in Zabrze, Medical University of Silesia, Katowice, \\ Silesian Centre for Heart Diseases, Zabrze, Poland
}

Adv Interv Cardiol 2018; 14, 4 (54): 347-355

DOI: https://doi.org/10.5114/aic.2018.79194

\begin{abstract}
A bstract
Introduction: The biodegradable polymer drug-eluting stents were developed to improve vascular healing. However, further data are needed to confirm the safety and efficacy of these stents in patients with acute myocardial infarction (AMI).

Aim: We sought to determine the 1-year clinical follow-up in patients with AMI treated with a thin strut biodegradable polymer-coated sirolimus-eluting stent (BP-SES) versus a durable coating everolimus-eluting stent (DP-EES).

Material and methods: We analyzed patients with AMI (STEMI and NSTEMI) treated with either a BP-SES (ALEX, Balton, Poland, $n=886$ ) or DP-EES (XIENCE, Abbott, USA, $n=1054$ ) with available 1-year clinical follow-up using propensity score matching. Outcomes included target vessel revascularization (TVR) as the efficacy outcome and all-cause death, myocardial infarction, and definite/probable stent thrombosis as safety outcomes.

Results: After propensity score matching 672 patients treated with BP-SES and 672 patients treated with DP-EES were selected. Procedural and clinical characteristics were similar between the groups. In-hospital mortality was similar in both tested groups. Oneyear follow-up demonstrated comparable efficacy outcome TVR (BP-SES 7.1\% vs. DP-EES 5.2\%, $p=0.14$ ), as well as similar safety outcomes of all-cause death, myocardial infarction, and definite/probable stent thrombosis.

Conclusions: The thin-strut biodegradable polymer coated sirolimus-eluting stent demonstrated comparable clinical outcomes at 1 year after implantation to the DP-EES. These data support the relative safety and efficacy of BP-SES in AMI patients undergoing percutaneous coronary intervention.
\end{abstract}

Key words: acute myocardial infarction, bioabsorbable polymer, drug-eluting stents.

S u m m a ry

To date, there are few data regarding the comparison of the durable coating everolimus-eluting stent (DP-EES) with the biodegradable polymer-coated sirolimus-eluting stent (BP-SES) in the acute myocardial infarction (AMI) population. In our study, we conducted the first competitive evaluation of the thin strut BP-SES versus the leading DP-EES in the AMI setting. Up to one-year follow-up, the safety and efficacy outcomes did not differ between AMI patients implanted with BP-SES vs. BP-EES and further benefits might emerge in long-term follow-up.

Corresponding author:

Paweł Gąsior MD, PhD, Department of Cardiology and Structural Heart Diseases, Medical University of Silesia, 45/47 Ziołowa St, 40-635 Katowice, Poland, phone: +48600429 867, e-mail: p.m.gasior@gmail.com

Received: 20.07.2018, accepted: 19.09.2018. 


\section{Introduction}

The first generation drugeluting stents (DES) coated with a permanent polymer reduced rates of restenosis when compared to bare metal stents (BMS). Although DES succeeded in suppressing neointimal hyperplasia, the presence of durable polymers was attributed to delayed vessel healing, hypersensitivity reactions, chronic inflammation with the added risks of stent thrombosis (ST) due to delayed healing and prolonged re-endothelialization [1-5]. Second-generation DES reduced rates of ST with preserved low restenosis rates [6-8]. However, very late ST and neoatherosclerosis have been recently observed also with second-generation DES [9-11]. To address the limitations of the durable polymer DES, new platforms that make use of biodegradable polymers have been developed. The safety and effectiveness of biodegradable polymer coated DES (BP-DES) over BMS and first-generation DES has been proven previously in reducing the risk of very late ST and restenosis [12-14]. Patients with acute coronary syndromes (ACS) constitute a challenging subset with poorer outcomes after percutaneous coronary interventions (PCI) as compared to stable coronary artery disease, with an increased risk of ST and reinfarction [15]. Therefore, despite the potential benefits of a BP-DES in patients with acute myocardial infarction (AMI), their efficacy and safety remain to be confirmed.

\section{Aim}

In our study, we sought to determine the 1-year clinical follow-up of patients treated with the thin strut BP-coated sirolimus-eluting stent (BP-SES) versus the durable coating everolimus-eluting stent (DP-EES) in the AMI setting, including ST-segment elevation myocardial infarction (STEMI) and non-STEMI patients (NSTEMI).

\section{Material and methods}

\section{Study design}

The data were obtained from a prospective, observational registry of all patients treated with $\mathrm{PCl}$ in four interventional cardiology centers in Poland (Sosnowiec, Raciborz, Chorzow, Czestochowa) without cardiac surgery on site. We performed a retrospective screening of unselected individuals $(n=21400)$ treated with PCI between 2010 and 2016. We included all consecutive patients with AMI (STEMI and NSTEMI) who underwent single or multi-vessel revascularization with either a BP-SES (ALEX, Balton, Warsaw, Poland) or a DP-EES (XIENCE, Abbott Vascular, Santa Clara, CA) during the index procedure. Relative contributions of the centers in terms of number of patients included were as follows: Czestochowa 39.3\%, Sosnowiec $28.8 \%$, Chorzow $16.1 \%$ and Raciborz $15.8 \%$. Follow-up data for patients treated in the years 20152016 are currently not available. Therefore, for the final analysis only patients treated between 2010 and 2014 were selected, because 1-year follow-up data were available for all the patients. Due to the observational nature of the study and lack of any interference in the diagnostic and therapeutic decision-making process no permission was required from the Institutional Review Board and Bioethics Committee.

\section{Stent system description}

The BP-SES used in this study is a CE-approved balloon expandable cobalt-chromium stent with a $71 \mu \mathrm{m}$ strut thickness and metal-to-artery ratio of $\approx 19 \%$. It is covered with a biodegradable copolymer of poly-lactic and glycolic acid together with sirolimus. Preclinical studies in the porcine in-stent restenosis model at eight weeks showed nearly full polymer biodegradation and $95 \%$ release of the initial drug load [16]. In the previously published study, the BP-SES demonstrated favorable performance in complex coronary lesions of 424 patients in daily clinical practice [17]. The BP-SES demonstrated low residual diameter stenosis $(6.43 \pm 4.16 \%)$ together with high clinical device success (98.5\%), and acute gain (1.67 $\pm 0.44 \mathrm{~mm}$ ). In the present study, the thin strut BP-SES was compared to the benchmark balloon-expandable cobalt-chromium DP-EES with strut thickness of $81 \mu \mathrm{m}$ and a metal-to-artery ratio of $\approx 15 \%$. Everolimus is blended in a non-erodible polymer coated over another non-erodible polymer primer layer. The coating consists of acrylic and fluoropolymers and everolimus is eluted up to 120 days.

\section{Study population}

The demographic, clinical and angiographic data collected in the course of the index hospitalization were retrieved from the prospectively recorded Institutional Electronic Database. Follow-up data were retrieved from the health insurer (National Health Fund) database including the exact dates for deaths, myocardial infarction (MI) and repeat revascularization. Detailed angiographic data for repeat revascularization were obtained from the medical centers that performed the procedures.

All patients underwent coronary angiography with following or postponed PCl using standard devices. All interventional strategies, including the use of stents, choice of stent type and periprocedural antithrombin and antiplatelet therapy, were at the discretion of the attending physicians. Pharmacological treatments recommended by the European Society of Cardiology were introduced before and after the intervention unless contraindicated.

\section{Definitions and endpoints}

Target vessel revascularization (TVR) served as the efficacy outcome. Death, myocardial infarction (MI), and definite or probable ST were safety outcomes. MI was defined according to the European Society of Cardiology/ American College of Cardiology criteria for $\mathrm{Ml}$ and that 
was clinically distinct from the index event at the time of first hospitalization [18]. Target vessel revascularization was defined as any repeat percutaneous intervention or surgical bypass of any segment of the target vessel including ischemia-driven and symptomatic-driven intervention. ST was considered as acute (0-24 h), subacute (> $24 \mathrm{~h}$ to 30 days) or late (> 31 days) and was defined as either definitive or probable according to the Academic Research Consortium [19].

\section{Statistical analysis}

Categorical variables are presented as percentages and were compared using the $\chi^{2}$ test, whereas continuous variables are displayed as means \pm SD and were compared using Student's $t$-test. A propensity score method was used to match the BP-SES and DP-EES groups for all baseline clinical characteristics and angiographic parameters listed in Tables I and II. The area under the curve for the logistic model was 0.708 (95\% confidence interval 0.686 to 0.731$), p<0.0001$. The greedy matching algorithm, available in NCSS, was used with the distance calculation option set to "Mahalanobis Distance within Propensity Score Calipers (no matching outside caliper)" and caliper to $0.2^{*}$ Sigma. Cumulative event rates in 1-year fol- low-up were analyzed with the Kaplan-Meier method and compared with the log-rank test. All tests were 2-tailed, and a $p$-value $<0.05$ was considered to indicate statistical significance. Statistics were calculated with Statistica 12 (StatSoft, Tulsa, Oklahoma, USA) and NCSS 12 Statistical Software (NCSS, LLC. Kaysville, Utah, USA).

\section{Results}

\section{Baseline demographic characteristics}

A total of 886 BP-SES and 1054 DP-EES patients were found to be eligible for matching. There was no difference in terms of age between the two tested groups (BP-SES $66.05 \pm 11.04$ vs. DP-EES $65.34 \pm 11.24 ; p=0.16$ ). There was a significantly higher incidence of ST-segment elevation myocardial infarction in the BP-SES group $(35.4 \%$ vs. $26.9 \% ; p<0.001)$ at hospital admission when compared to the DP-EES group. Previous stroke was present more often in the BP-SES than the DP-EES group $(6.0 \%$ vs. $3.6 \% ; p=0.01$ ). Previous $\mathrm{MI}$ and $\mathrm{PCl}$ procedures were less common in the BP-SES group (respectively: $25.2 \%$ vs. $30.8 \% ; p=0.01,14.0 \%$ vs. $22.8 \% ; p<0.001$ ).

Following propensity score analysis and matching, 672 pairs were selected for further analysis with a mean age of $65.72 \pm 11.24$ years in the BP-SES group and

Table I. Baseline characteristics

\begin{tabular}{|c|c|c|c|c|c|c|}
\hline \multirow[t]{2}{*}{ Parameter } & \multicolumn{3}{|c|}{ Unmatched cohort } & \multicolumn{3}{|c|}{ Matched cohort } \\
\hline & $\begin{array}{c}\text { BP-SES } \\
(n=886)\end{array}$ & $\begin{array}{c}\text { DP-EES } \\
(n=1054)\end{array}$ & $P$-value & $\begin{array}{c}\text { BP-SES } \\
(n=672)\end{array}$ & $\begin{array}{c}\text { DP-EES } \\
(n=672)\end{array}$ & $P$-value \\
\hline Age, mean \pm SD [years] & $66.05 \pm 11.04$ & $65.34 \pm 11.24$ & 0.16 & $65.72 \pm 11.24$ & $65.88 \pm 11.19$ & 0.78 \\
\hline Female (\%) & 37.8 & 34.4 & 0.12 & 34.1 & 37.1 & 0.25 \\
\hline Previous MI (\%) & 25.2 & 30.8 & 0.01 & 27.8 & 28.0 & 0.95 \\
\hline Previous PCI (\%) & 14.0 & 22.8 & $<0.001$ & 16.7 & 17.3 & 0.77 \\
\hline Previous bypass surgery (\%) & 8.7 & 9.9 & 0.37 & 8.8 & 9.5 & 0.64 \\
\hline Previous stroke (\%) & 6.0 & 3.6 & 0.01 & 4.7 & 4.6 & 0.90 \\
\hline Hypertension (\%) & 77.1 & 76.5 & 0.75 & 76.2 & 76.3 & 0.95 \\
\hline Diabetes (\%) & 30.8 & 35.5 & 0.03 & 32.9 & 32.7 & 0.95 \\
\hline Hypercholesterolemia (\%) & 42.9 & 46.6 & 0.10 & 44.6 & 43.3 & 0.75 \\
\hline Smoking (\%) & 27.9 & 18.8 & $<0.001$ & 23.5 & 22.9 & 0.62 \\
\hline Obesity (\%) & 26.1 & 30.7 & 0.01 & 26.9 & 26.6 & 0.90 \\
\hline Chronic heart failure (\%) & 23.8 & 24.2 & 0.85 & 23.7 & 23.7 & 1.00 \\
\hline Chronic renal failure (\%) & 9.4 & 10.6 & 0.36 & 9.5 & 10.3 & 0.64 \\
\hline Cardiogenic shock (\%) & 3.7 & 2.8 & 0.22 & 2.7 & 3.7 & 0.28 \\
\hline \multicolumn{7}{|l|}{ Indication for procedure (\%): } \\
\hline STEMI & 35.4 & 26.94 & $<0.001$ & 30.9 & 30.5 & 0.86 \\
\hline NSTEMI & 69.3 & 76.38 & $<0.001$ & 72.9 & 72.6 & 0.90 \\
\hline
\end{tabular}

MI-myocardial infarction, STEMI - ST segment elevation myocardial infarction, NSTEMI - non-ST segment elevation myocardial infarction. 
Table II. Angiographic and procedural characteristics

\begin{tabular}{|c|c|c|c|c|c|c|}
\hline \multirow[t]{2}{*}{ Parameter } & \multicolumn{3}{|c|}{ Unmatched cohort } & \multicolumn{3}{|c|}{ Matched cohort } \\
\hline & $\begin{array}{l}\text { BP-SES } \\
(n=886)\end{array}$ & $\begin{array}{c}\text { DP-EES } \\
(n=1054)\end{array}$ & $P$-value & $\begin{array}{l}\text { BP-SES } \\
(n=886)\end{array}$ & $\begin{array}{c}\text { DP-EES } \\
(n=1054)\end{array}$ & $P$-value \\
\hline Multi-vessel CAD (\%) & 68.1 & 69.4 & 0.54 & 67.6 & 68.2 & 0.82 \\
\hline LM CAD (\%) & 4.1 & 7.4 & $<0.01$ & 4.8 & 4.8 & 0.99 \\
\hline \multicolumn{7}{|l|}{ Target vessel (\%): } \\
\hline LM & 1.9 & 6.5 & $<0.01$ & 2.4 & 2.2 & 0.86 \\
\hline LAD & 28.3 & 44.1 & $<0.01$ & 33.0 & 33.3 & 0.91 \\
\hline$C x$ & 31.4 & 27.4 & 0.05 & 30.1 & 29.9 & 0.68 \\
\hline RCA & 42.9 & 32.4 & $<0.01$ & 38.9 & 38.1 & 0.74 \\
\hline Bypass & 4.2 & 3.1 & 0.22 & 3.7 & 4.0 & 0.78 \\
\hline Single vessel PCI (\%) & 79.8 & 74.9 & 0.40 & 78.9 & 80.7 & 0.41 \\
\hline Bifurcation PCI (\%) & 10.5 & 18.50 & $<0.01$ & 11.8 & 11.3 & 0.80 \\
\hline Stents used per patient, mean \pm SD & $1.53 \pm 0.88$ & $1.52 \pm 0.83$ & 0.64 & $1.52 \pm 0.86$ & $1.50 \pm 0.81$ & 0.60 \\
\hline Total length of stents, mean \pm SD & $29.10 \pm 18.63$ & $32.31 \pm 19.79$ & $<0.01$ & $30.18 \pm 19.25$ & $30.00 \pm 17.92$ & 0.86 \\
\hline $\begin{array}{l}\text { Maximal implantation pressure, } \\
\text { mean } \pm \text { SD }\end{array}$ & $14.58 \pm 2.23$ & $14.67 \pm 2.58$ & 0.52 & $14.62 \pm 2.21$ & $14.53 \pm 2.58$ & 0.57 \\
\hline Direct stent implantation (\%) & 33.4 & 29.9 & 0.1 & 31.1 & 31.2 & 0.72 \\
\hline Post-dilatation (\%) & 23.9 & 25.0 & 0.57 & 22.8 & 24.4 & 0.49 \\
\hline Thrombectomy (\%) & 9.9 & 9.3 & 0.63 & 9.7 & 9.5 & 0.93 \\
\hline $\begin{array}{l}\text { Procedural glycoprotein IIb/IIIa } \\
\text { inhibitor (\%) }\end{array}$ & 8.3 & 11.0 & 0.05 & 9.0 & 9.9 & 0.56 \\
\hline
\end{tabular}

$C A D$ - coronary artery disease, $L M$ - left main, $L A D$ - left anterior descending, $C x$-circumflex, RCA - right coronary artery, $P C l$ - percutaneous coronary intervention.

$65.88 \pm 11.19$ in the DP-EES group. No significant differences were found in the baseline characteristics following matching. The proportions of patients with STEMI (BP-SES 30.9\% vS. DP-EES 30.5\%) and NSTEMI (BP-SES $72.9 \%$ vs. DP-EES $72.6 \%)$ were not different between matched groups. An overview of the unmatched and matched baseline characteristics is presented in Table I.

\section{Patients angiographic and procedural characteristics}

Before propensity score matching, there were significant differences between BP-SES and DP-EES groups in angiographic and procedural characteristics. Left main coronary artery disease occurred less frequently in the BP-SES group than the DP-SES group. The rate of single vessel PCI was higher in the BP-DES group than the DPEES group. The number of stents implanted per patient was similar between the groups.

After propensity score matching, angiographic and procedural characteristics such as a multi-vessel CAD, left main CAD and targeted vessels were comparable between studied groups. There was no difference in single-vessel intervention rates. There was no difference in the number and length of stents implanted per patient. Angiographic and procedural characteristics before and after propensity score matching are summarized in Table II.

\section{Clinical outcomes in matched cohorts}

In-hospital (BP-SES 3.1\% vs. DP-EES 2.5\%; $p=0.43$ ) and 30-day mortality (BP-SES $3.9 \%$ vS. DP-EES $2.5 \%$; $p=0.16)$ was comparable in the matched groups. The efficacy outcome of TVR rates at 12 months did not differ significantly between BP-SES and DP-EES groups (respectively: $7.1 \%$ vs. $5.2 \%, p=0.14$ ). There was also no difference in safety endpoints between the matched groups regarding death, $\mathrm{MI}$, and definite/probable ST (Figure 1). All-cause mortality at 1 year was identical in both groups (BP-SES $8.5 \%$ vs. DP-EES 8.5\%, $p=1.00$ ). Myocardial infarction rates were comparable in both groups (BP-SES $8.3 \%$ vs. DP-EES $8.0 \% ; p=0.84)$. The cumulative rates of definite/probable ST were relatively low with no significant difference between the matched groups (BP-SES $2.5 \%$ vs. DP-SES $2.2 \% ; p=0.72$ ). Also, there was no difference in acute (BP-SES 0.2\% vs. DP-SES $0.2 \% ; p=1.00$ ), subacute (BP-SES $1.2 \%$ vs. DP-SES $1.2 \% ; p=1.00$ ) and late (BP-SES $1.2 \%$ vs. DP-SES $0.9 \% ; p=0.59$ ) definite/ 
A

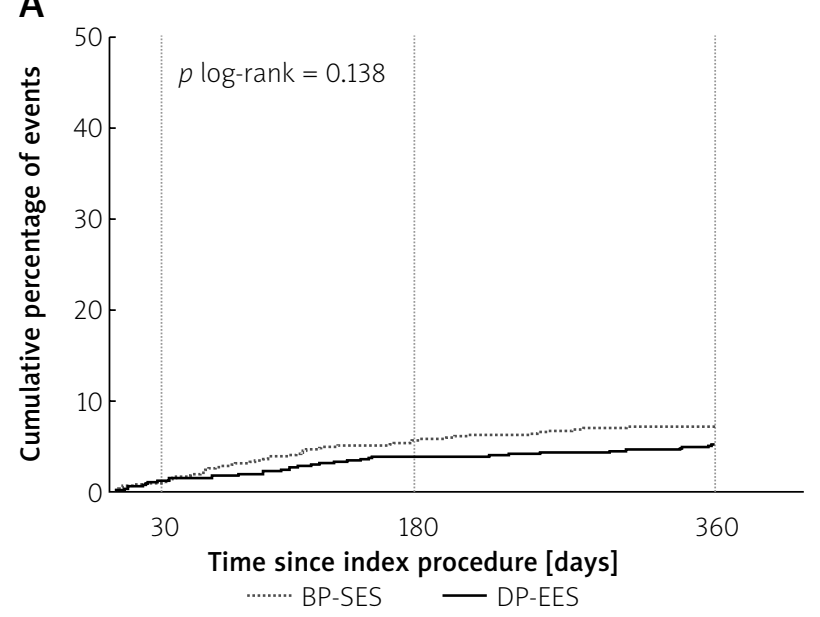

Patients at risk:

$\begin{array}{lcclllll}\text { Days } & 0 & 60 & 120 & 180 & 240 & 300 & 360 \\ \text { BP-SES } & 672 & 664 & 657 & 648 & 646 & 643 & 641 \\ \text { DP-EES } & 672 & 666 & 648 & 638 & 631 & 627 & 624\end{array}$

C

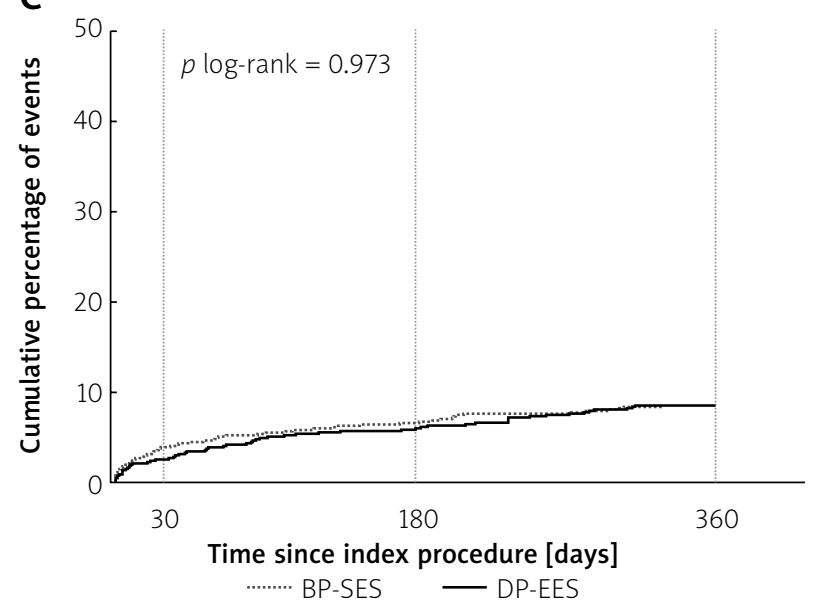

Patients at risk:

$\begin{array}{lccccccc}\text { Days } & 0 & 60 & 120 & 180 & 240 & 300 & 360 \\ \text { BP-SES } & 672 & 655 & 639 & 634 & 630 & 622 & 615 \\ \text { DP-EES } & 672 & 646 & 636 & 629 & 631 & 621 & 615\end{array}$

B

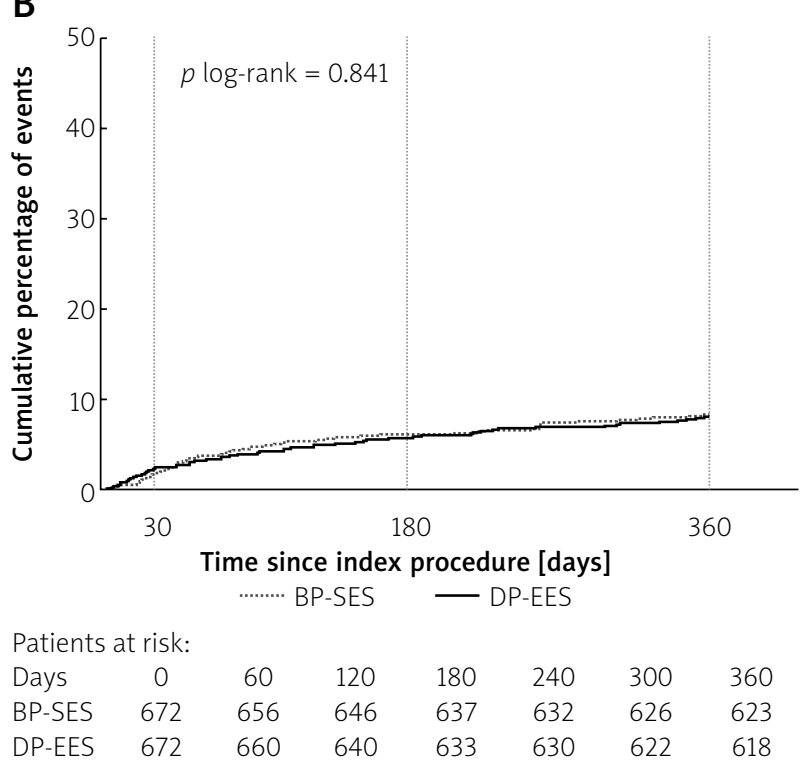

D

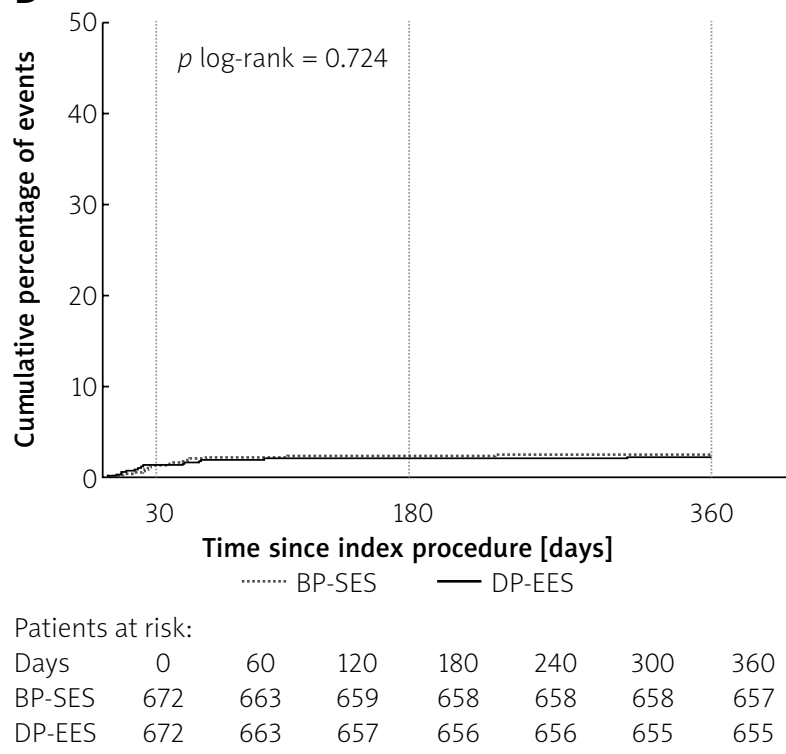

Figure 1. 1-year Kaplan-Meier event rates. Kaplan-Meier curves show the cumulative incidence of target vessel revascularization (A), myocardial infarction (B), all-cause death (C) and definite/probable stent thrombosis (D)

probable ST. In summary, no significant differences were found in terms of clinical outcomes after 1 year. Detailed follow-up results are presented in Table III.

\section{Discussion}

The present study describes a direct comparison of the clinical outcomes of a thin strut biodegradable polymer coated sirolimus-eluting stent against the benchmark non-erodible polymer coated everolimus-eluting stent in AMI patients. The major finding of this investigation in a propensity-matched cohort is comparable 1-year clinical outcomes for the BP-SES when compared with the DP-EES, with relatively low event rates, demonstrating similar safety and efficacy of the devices in the AMI setting.
The ACS patients are more likely to develop subsequent coronary events such as ST leading to reinfarction. Intravascular imaging studies demonstrated impaired vessel healing in STEMI patients after DES implantation with a higher proportion of uncovered struts, which was most likely related to the adverse vessel remodeling caused by hypersensitivity and attenuation of the vessel's healing process induced by the polymer [20]. The ACS patients display persistent inflammation and high platelet reactivity, which favors the use of dual antiplatelet therapy (DAPT) for a longer time. Multiple meta-analyses have examined the impact of prolonged DAPT after DES implantation on clinical outcomes [21-23]. These studies have demonstrated that prolonged DAPT was as- 
Table III. Clinical outcomes at 30 days, 6 months, and 12 months in propensity matched cohort

\begin{tabular}{llll} 
Parameter & BP-SES $(n=672)$ & DP-EES $(n=672)$ & $P$-value \\
\hline 30 days, $n$ (\%): & & $8(1.2)$ & 0.59 \\
\hline TVR & $6(0.9)$ & $16(2.4)$ & 0.44 \\
\hline Myocardial infarction & $12(1.8)$ & $17(2.5)$ & 0.16 \\
\hline All-cause death & $26(3.9)$ & $26(3.9)$ & 0.12 \\
\hline $\begin{array}{l}\text { months, } n \text { (\%): } \\
\text { TVR }\end{array}$ & $38(5.7)$ & $38(5.7)$ & 0.73 \\
\hline Myocardial infarction & $41(6.1)$ & $40(6.0)$ & 0.65 \\
\hline All-cause death & $44(6.6)$ & & 0.14 \\
\hline 12 months, $n$ (\%): & $48(7.1)$ & $35(5.2)$ & 0.84 \\
\hline TVR & $56(8.3)$ & $54(8.0)$ & 1.00 \\
\hline Myocardial infarction & $57(8.5)$ & $57(8.5)$ & 0.72 \\
\hline All-cause death & $17(2.5)$ & $15(2.2)$ & 1.00 \\
\hline Definite/probable stent thrombosis, $n(\%):$ & $1(0.2)$ & $1(0.2)$ & 1.00 \\
\hline Acute (0-1 day) & $8(1.2)$ & $8(1.2)$ & 0.59 \\
\hline Subacute (2-30 days) & $8(1.2)$ & $6(0.9)$ & \\
\hline Late (31-365 days) & & & \\
\hline
\end{tabular}

TVR-target vessel revascularization.

sociated with a lower risk of stent thrombosis and AMI compared with shorter therapy. However, this benefit was attenuated with second-generation DES when compared to the first-generation DES. Ischemic event benefit was offset by a higher risk of bleeding and all-cause mortality when compared with shorter-duration therapy. The optimal duration of DAPT in patients at high risk of bleeding remains unknown. Therefore, the concept of a platform that offers benefits of DES in terms of reduction of restenosis and repeat revascularization together with the BMS safety regarding the risk of late thrombosis seems very attractive. Moreover, this might potentially result in a reduction of DAPT duration in ACS patients with high bleeding risk.

A large meta-analysis demonstrated a favorable safety profile of BP-DES together with a reduction of definite or probable ST when compared to bare metal stents [24]. Also, no differences in the rate of ST at median follow-up of 20 (18-30) months were observed when comparing second generation DES and BP-DES (OR $=0.4,0.1-1.3)$ [25]. However, a recent analysis of ST rates reported to the Manufacturer and User Facility Device Experience database raised the possibility of an increased risk of ST, particularly as it relates to early ST (within 2-24 h) after implantation of a biodegradable polymer-coated everolimus-eluting stent (BP-EES) when compared to second generation DES [26]. In the subgroup of ACS patients of the COMPARE II trial, the biodegradable polymer bi- olimus-eluting stent was noninferior to the durable fluoropolymer-based everolimus-eluting stent at 12 months [27]. Also, results from a large and unselected cohort of patients with myocardial infarction treated with BPEES demonstrated similar stent performance and clinical outcomes up to two years when compared to other newer-generation DES [28]. In the pooled individual patient-level analysis from three randomized clinical trials comparing BP-DES with DP-DES in 497 STEMI patients at 4 years, major adverse cardiac events were significantly reduced following treatment with BP-DES (hazard ratio $(H R)=0.59,95 \% \mathrm{Cl}: 0.39-0.90 ; p=0.01)$ [29]. Furthermore, non-significant reductions of cardiac death or MI (BP-DES 9.5\% vs. DP-DES 15.0\%; $p=0.07$ ) and definite or probable ST (BP-DES 3.6\% vs. DP-DES 7.1\%; $p=$ 0.09 ) in the BP-DES group were demonstrated. In the CENTURY II high-risk ACS substudy, BP-DES demonstrated noninferiority to DP-DES regarding major adverse cardiac events at 24 months and a favorable safety profile as evidenced by similar rates of ST throughout 2 years [30]. In our study, BP-SES demonstrated similar efficacy to DP-EES described by comparable TVR rates in both studied groups (respectively: $7.1 \%$ vs. $5.2 \%, p=0.14$ ). Also, we found that treatment with BP-SES was not associated with increased mortality (respectively: $8.5 \%$ vs. $8.5 \%$; $p=1.00$ ) and $\mathrm{MI}$ rates (respectively: $8.3 \%$ vs. $8.00 \%$; $p=0.84)$ compared to DP-EES. Furthermore, no significant differences were found in terms of definite and 
probable stent thrombosis (BP-SES $2.5 \%$ vs. DP-SES $2.2 \%$; $p=0.72$ ). However, the 12 -month rates of stent thrombosis found in our study are slightly higher than in randomized trials comparing biodegradable and durable polymer coated DES [31]. It is important to stress that this difference might be attributed to a more challenging population comprising only AMI patients.

Acute thrombogenicity and long-term vascular healing in DES have been attributed not only to drug pharmacokinetics, durable polymer biocompatibility, composition distribution, and, in the case of BP-DES, duration of bioresorption, but also to the platform material and stent strut thickness [32-34]. Indeed, compared with the thicker struts, thinner strut platforms have been shown to reduce platelet aggregation and inflammatory cell adhesion $[35,36]$. The BP-SES evaluated in this study was designed to facilitate stent vascular healing using a thinner strut profile $(71 \mu \mathrm{m})$ compared to the DP-EES $(81 \mu \mathrm{m})$. A previously published multi-timepoint optical coherence tomography (OCT) study of arterial wall healing after implantation of BP-SES out to 12 months demonstrated a favorable profile of arterial wall healing already after 3 months, while retaining a sustained antiproliferative effect up to 12 months of follow-up [37]. Whether the degree of strut coverage (evaluated by OCT) is a sufficient parameter to discontinue DAPT without the risk of ST safely is currently not known and needs to be appropriately assessed in a prospective clinical trial. It also remains to be demonstrated whether the use of new technologies such as BP with thin-strut stent platforms, seeking to achieve more rapid re-endothelialization and an improved healing pattern, will overcome the small drawbacks of the current DES generation in terms of ST and stent restenosis. One of the biggest differences between studied devices is the type of antiproliferative drug eluted from the stent surface (sirolimus vs. everolimus). Safety data from large meta-analysis favor the use of everolimus vs. sirolimus eluting stents [38]. However, most of the differences in device performance are explained by the type and design of metallic platforms or polymers used in these devices. Therefore, we believe that in the setting of thinner strut thickness and improved stent design the overall drug effect of both limus analogues is not significantly different.

It has been previously postulated that longer follow-up is required to demonstrate the risk reduction of adverse events in favor of BP-DES compared with DP-DES [13]. For example, the 5-year results in the LEADERS trial showed that BP-DES was associated with a significant reduction in very late ( $>1$ year) definite stent thrombosis [39]. Therefore, follow-up beyond 1 year is required to clarify the potential benefit of BP-SES over DP-EES on clinical outcomes.

Taking into consideration the above observations in a propensity-matched cohort, we are of the opinion that the BP-SES included in the present study displays a similar efficacy profile as the benchmark DP-EES, without compromising safety, which is of the utmost importance among $\mathrm{AMI}$ patients treated in routine clinical practice.

\section{Study limitations}

First, our study is limited by its observational nature and patients were not enrolled in a randomized fashion. Thus, any findings should be confirmed by a prospective and sufficiently powered clinical trial. Nevertheless, more challenging patients are often excluded from randomized controlled trials. For such reasons, observational studies can be used as complementary forms of research in the real-world population [40]. We attempted to minimize the selection bias as regards whether to implant a BP-SES or a DP-EES by using propensity score matching for a wide range of variables. However, not all differences between the groups can be addressed.

Second, no routine angiographic surveillance was scheduled, and thus no conclusions regarding potential restenosis can be made. Also, no intravascular imaging data were collected. Adequate DAPT is one of the most important factors that prevent stent thrombosis. However, we do not have the data on antiplatelet drug compliance during follow-up.

Third, we evaluated only patients treated between 2010 and 2014 due to the lack of currently available follow-up for 546 patients treated in the years 2015-2016.

Fourth, no data on cardiovascular mortality, stroke or major bleeding at follow-up were available.

Finally, our study is limited to one-year follow-up, while the theoretical differential clinical outcome between the compared technologies might be observed during long-term follow-up.

\section{Conclusions}

This is the first competitive evaluation of BP-SES vs. DP-EES in the AMI population. It provides evidence for the safety and efficacy of the BP-SES. The 12-month outcomes for the BP-SES were similar to the DP-EES. These findings should be verified in a prospective, randomized trial.

\section{Conflict of interest}

The authors declare no conflict of interest.

\section{References}

1. Nebeker JR, Virmani R, Bennett CL, et al. Hypersensitivity cases associated with drug-eluting coronary stents: a review of available cases from the Research on Adverse Drug Events and Reports (RADAR) project. J Am Coll Cardiol 2006; 47: 175-81.

2. Nordmann AJ, Briel M, Bucher HC. Mortality in randomized controlled trials comparing drug-eluting vs. bare metal stents in coronary artery disease: a meta-analysis. Eur Heart J 2006; 27 : 2784-814. 
3. Serruys PW, Daemen J. Are drug-eluting stents associated with a higher rate of late thrombosis than bare metal stents? Late stent thrombosis: a nuisance in both bare metal and drug-eluting stents. Circulation 2007; 115: 1433-9.

4. Camenzind E, Steg PG, Wijns W. Stent thrombosis late after implantation of first-generation drug eluting stents: a cause for concern. Circulation 2007; 115: 1440-55.

5. Park SJ, Kang SJ, Virmani R, et al. In-stent neoatherosclerosis: a final common pathway of late stent failure. J Am Coll Cardiol 2012; 59: 2051-7.

6. Räber L, Magro M, Stefanini GG, et al. Very late coronary stent thrombosis of a newer-generation everolimus-eluting stent compared with early-generation drug-eluting stents: a prospective cohort study. Circulation 2012; 125: 1110-21.

7. Stefanini GG, Windecker S. Stent thrombosis: no longer an issue with newer-generation drug-eluting stents? Circ Cardiovasc Interv 2012; 5: 332-5.

8. Dores H, Raposo L, Campante Teles R, et al. Stent thrombosis with second- versus first- generation drug-eluting stents in realworld percutaneous coronary intervention: analysis of 3806 consecutive procedures from a large-volume single-center prospective registry. J Invasive Cardiol 2013; 25: 330-6.

9. Naidu SS, Krucoff MW, Rutledge DR, et al. Contemporary incidence and predictors of stent thrombosis and other major adverse cardiac events in the year after XIENCE $V$ implantation: results from the 8,061-patient XIENCE V United States study. J Am Coll Cardiol Intv 2012; 5: 626-35.

10. Nakazawa G, Otsuka F, Nakano M, et al. The pathology of neoatherosclerosis in human coronary implants bare-metal and drug-eluting stents. J Am Coll Cardiol 2011; 57: 1314-22.

11. Park SJ, Kang SJ, Virmani R, et al. In-stent neoatherosclerosis: a final common pathway of late stent failure. J Am Coll Cardiol 2012; 59: 2051-7.

12. Räber L, Kelbæk H, Ostojic M, et al. Effect of biolimus-eluting stents with biodegradable polymer vs bare-metal stents on cardiovascular events among patients with acute myocardial infarction: the COMFORTABLE AMI randomized trial. JAMA 2012; 308: 777-87.

13. Stefanini GG, Byrne RA, Serruys PW, et al. Biodegradable polymer drug-eluting stents reduce the risk of stent thrombosis at 4 years in patients undergoing percutaneous coronary intervention: a pooled analysis of individual patient data from the ISAR-TEST 3, ISARTEST 4, and LEADERS randomized trials. Eur Heart J 2012; 33: 1214-22.

14. Palmerini T, Biondi-Zoccai G, Della Riva D, et al. Clinical outcomes with bioabsorbable polymer-versus durable polymer-based drug-eluting and bare- metal stents: evidence from a comprehensive network meta-analysis. J Am Coll Cardiol 2014; 63: 299-307.

15. Kukreja N, Onuma Y, Garcia-Garcia HM, et al. Interventional Cardiologists of the Thoraxcenter (2000 to 2005). The risk of stent thrombosis in patients with acute coronary syndromes treated with bare-metal and drug-eluting stents. JACC Cardiovasc Interv 2009; 2: 534-41.

16. Orlik B, Buszman PP, Krauze A, et al. A nuclear magnetic resonance spectroscopy as a method for evaluation of in vivo poly-l-lactide biodegradation kinetics from stent-polymer matrices: an experimental study utilizing porcine model of in-stent restenosis. J Cardiovasc Pharmacol Ther 2016; 21: 93-9.

17. Hawranek M, Desperak P, Ciślak A, et al. Safety and efficacy of a second-generation coronary sirolimus-eluting stent with bio- degradable polymers in daily clinical practice: a 12-month follow-up of the ALEX registry. Coron Artery Dis 2016; 27: 89-94.

18. Thygesen K, Alpert JS, Jaffe AS, et al. Third universal definition of myocardial infarction. Eur Heart J 2012; 33: 2551-67.

19. Cutlip DE, Windecker S, Mehran R, et al. Academic Research Consortium. Clinical end points in coronary stent trials: a case for standardized definitions. Circulation 2007; 115: 2344-51.

20. Attizzani GF, Capodanno D, Ohno Y, et al. Mechanisms, pathophysiology, and clinical aspects of incomplete stent apposition. J Am Coll Cardiol 2014; 63: 1355-67.

21. Giustino G, Baber U, Sartori S, et al. Duration of dual antiplatelet therapy after drug-eluting stent implantation: a systematic review and meta-analysis of randomized controlled trials. J Am Coll Cardiol 2015; 65: 1298-310.

22. Navarese EP, Andreotti F, Schulze V, et al. Optimal duration of dual antiplatelet therapy after percutaneous coronary intervention with drug eluting stents: meta-analysis of randomised controlled trials. Br Med J 2015; 350: h1618-8.

23. Palmerini T, Benedetto $U$, Bacchi-Reggiani L, et al. Mortality in patients treated with extended duration dual antiplatelet therapy after drug-eluting stent implantation: a pairwise and Bayesian network meta-analysis of randomised trials. Lancet 2015; 385: 2371-82.

24. Kang SH, Chae IH, Park JJ, et al. Stent thrombosis with drug-eluting stents and bioresorbable scaffolds: evidence from a network meta-analysis of 147 trials. JACC Cardiovasc Interv 2016; 9: 1203-12.

25. D’Ascenzo F, lannaccone M, Saint-Hilary G, et al. Impact of design of coronary stents and length of dual antiplatelet therapies on ischaemic and bleeding events: a network meta-analysis of 64 randomized controlled trials and 102735 patients. Eur Heart J 2017; 38: 3160-72.

26. Khan AR, Tripathi A, Farid TA, et al. Stent thrombosis with bioabsorbable polymer drug-eluting stents: insights from the Food and Drug Administration database. Coron Artery Dis 2017; 28: 564-9.

27. Smits PC, Hofma S, Togni $M$, et al. Abluminal biodegradable polymer biolimus-eluting stent versus durable polymer everolimus-eluting stent (COMPARE II): a randomised, controlled, non-inferiority trial. Lancet 2013; 381: 651-60.

28. Buccheri S, Sarno G, Lagerqvist B, et al. Bioabsorbable polymer everolimus-eluting stents in patients with acute myocardial infarction: a report from the Swedish Coronary Angiography and Angioplasty Registry. Eurolntervention 2018; 14: e562-9.

29. de Waha A, King LA, Stefanini GG, et al. Long term outcomes of biodegradable versus durable polymer drug-eluting stents in patients with acute ST-segment elevation myocardial infarction: a pooled analysis of individual patient data from three randomised trials. Eurolntervention 2015; 10: 1425-31.

30. Jiménez VA, Iñiguez A, Baz JA, et al. A randomized comparison of novel bioresorbable polymer sirolimus-eluting stent and durable polymer everolimus-eluting stent in patients with acute coronary syndromes: the CENTURY II high risk ACS substudy. Cardiovasc Revasc Med 2016; 17: 355-61.

31. Christiansen E, Jensen LO, Thayssen P, et al.; Scandinavian Organization for Randomized Trials with Clinical Outcome (SORT OUT) V investigators. Biolimus-eluting biodegradable polymer-coated stent versus durable polymer-coated sirolimus-eluting stent in unselected patients receiving percutaneous coronary intervention (SORT OUT V): a randomised non-inferiority trial. Lancet 2013; 381: 661-9. 
32. Mennuni MG, Pagnotta PA, Stefanini GG. Coronary stents: the impact of technological advances on clinical outcomes. Ann Biomed Eng 2016; 44: 488-96.

33. Xu B, Gao R, Yang Y, et al.; PANDA III Investigators. Biodegradable polymer-based sirolimus-eluting stents with differing elution and absorption kinetics: the PANDA III trial. J Am Coll Cardiol 2016; 67: 2249-58.

34. Serruys PW, Silber S, Garg S, et al. Comparison of zotarolimus-eluting and everolimus-eluting coronary stents. N Engl I Med 2010; 363: 136-46.

35. Koppara T, Cheng Q, Yahagi K, et al. Thrombogenicity and early vascular healing response in metallic biodegradable polymer-based and fully bioabsorbable drug-eluting stents. Circ Cardiovasc Interv 2015; 8: e002427.

36. Kolandaivelu K, Swaminathan R, Gibson WJ, et al. Stent thrombogenicity early in high-risk interventional settings is driven by stent design and deployment and protected by polymer-drug coatings. Circulation 2011; 123: 1400-9.

37. Legutko J, Gil RJ, Buszman PE, et al. An optical coherence tomography study of neointimal morphology and strut coverage at different time intervals from implantation of biodegradable polymer-coated sirolimus-eluting stents. Catheter Cardiovasc Interv 2018; 92: 302-9.

38. Zhang YJ, Zhu LL, Bourantas CV, et al. Impact of everolimus versus other rapamycin derivative-eluting stents on clinical outcomes in patients with coronary artery disease: a meta-analysis of 16 randomized trials. J Cardiol 2014; 64: 185-93.

39. Serruys PW, Farooq V, Kalesan B, et al. Improved safety and reduction in stent thrombosis associated with biodegradable polymer-based biolimus-eluting stents versus durable polymer-based sirolimus-eluting stents in patients with coronary artery disease: final 5-year report of the LEADERS (Limus Eluted From A Durable Versus ERodable Stent Coating) randomized, noninferiority trial. JACC Cardiovasc Interv 2013; 6: 777-89.

40. Concato J, Shah N, Horwitz RI. Randomized, controlled trials, observational studies, and the hierarchy of research designs. N Engl J Med 2000; 342: 1887-92. 